\title{
Gross Motor Skills Performance of Hong Kong Chinese Children 香港兒童的大肌肉運動能力表現
}

\author{
Allison Ka Yee WONG Siu Yin CHEUNG \\ Department of Physical Education, \\ Hong Kong Baptist University, HONGKONG \\ 黄嘉儀张小燕 \\ 香港浸會大學體育學系
}

\begin{abstract}
[曲
Abstract

The purpose of this study was to provide normative information regarding gross motor skills performance of Hong Kong Chinese children. The Test of Gross Motor Development-2 (TGMD-2; Ulrich, 2000) was administered to 1251 participants $(N=1251)$. After preliminary data screening, a total of 1228 cases $(N=1228)$ were used for further analysis. Mean scores of locomotor subtest, object control subtest and the total scale of the TGMD-2 indicated that the mastery level of gross motor skills tended to follow an age trend. Norm-referenced values of locomotor subtest, object control subtest and total scale of the TGMD-2, based on percentiles, were developed to provide a database for subsequent evaluation of children's gross motor skills performance.
\end{abstract}

\section{摘 要}

本研究之目的為探討香港兒童的大肌肉運動能力表現, 並為有關動作技能提供常模數據。是次研究選用由U1rich (2000) 設 計的「大肌肉動作發展測驗 - 二」(Test of Gross Motor Development-2; TGMD-2) 來評估1251名香港兒童的大肌肉運動能 力表現, 其中 1228 名參加者的測試成績被用作進一步數據分析。結果顯示兒童的大肌肉運動能力表現隨著年龄而提高; 本研究更 按參加者的年齡及性別計算「移動性基本動作技能」、「操作性基本動作技能」及「整體大肌肉動作發展」的百分位數, 這些數 據有助體育工作者了解香港兒童的大肌肉運動能力之發展狀沉。

Key words: gross motor skills, TGMD-2 and Chinese children

\section{Introduction}

Physical education is one of the key learning areas for pre-primary and primary education (Curriculum Development Council, 1996, 2002). It is a unique subject in that it can provide students with opportunities to develop gross motor skills. Gross motor skills acquisition is regarded as both a basis for and an end product of sound instruction in physical education (Barton, Fordyce $\&$ Kirby, 1999). The proficiency of gross motor skills is a prerequisite for children to experience success and enjoyment in organized and unorganized movement activities (Woodard \& Surburg, 2001).
The importance of developing wide range of gross motor skills was highlighted in Health and Physical Education in the New Zealand Curriculum (Ministry of Education, 1999). It suggested that mastery of qualified gross motor skills would "facilitate the development of physical competence" (Ministry of Education, 1999, p. 8). More importantly, the development of gross motor skills was regarded as a prominent element in ensuring that children were equipped with the competencies to incorporate and maintain regular physical activity throughout their lives (Taggart \& Keegan, 1997). It was clear that children who were physically active on a regular basis were healthier than those who were inactive. 
There was a critical need for elementary school physical educators to teach the fundamental motor skills (Olrich, 2002). In the study of Luedke (1980; $N=$ 144), it was found that instruction was effective to improve throwing pattern of participants. Kelly, Dagger, and Walkey (1989) found that preschool children made qualitative performance gains in six fundamental motor skills from pretest to posttest as a result of two 5-week instructional units consisting of direct instruction. ConnorKuntz and Dummer (1996) indicated significant qualitative performance gains in gross motor skills for children after an 8-week intervention. Information from gross motor skills assessment could be profitably used by physical educators in designing appropriate instructional experiences for children. However, there is no comprehensive data available to depict the mastery levels of gross motor skills of Hong Kong Chinese children across different age groups and gender. The purpose of this study was to develop normative scores in gross motor skills performance for children aged 3 to 10 years, using the Test of Gross Motor Development-2 (TGMD-2; Ulrich, 2000). These normative standards increase the usefulness of a testing instrument and improve the interpretability of test scores, since they provide information about the range of performance that can be expected of individuals with different ages and gender, as well as to allow comparison of a given individual's gross motor skills performance with the pre-established standards.

\section{Methods}

\section{Participants}

Participants were 1,251 Hong Kong Chinese children (692 boys and 559 girls), aged 3 to 10 years. Convenient sampling method was used in this study. The participants were recruited from 4 kindergartens and the 2005 YMCA of Hong Kong Summer Camp.

\section{Testing instrument}

The testing instrument used in this study was the second edition of the Test of Gross Motor Development (TGMD-2; Ulrich, 2000). It was a norm and criterionreferenced measure of gross motor skills. The TGMD-2 evaluated performance of six locomotor skills (Hop, Slide, Gallop, Jump, Leap and Run) and six object control skills (Dribble, Kick, Catch, Throw, Roll and Strike) for children aged 3 to 10 years. In the TGMD-2, each skill included performance criteria to qualitatively describe performance. Individual performance was scored with a 1 or 0 to show the presence or absence of that skill. The raw score for each skill test item was obtained by summing the scores of the two trials.

The raw score for each skill ranged from 6 to 10 points. Raw scores could be added up across skills to form a sub-set (locomotor or object control). The total raw score for locomotor and object control skills both ranged from 0 to 48 points. With regard to the test manual of TGMD-2 (Ulrich, 2000), the two sub-set raw scores could be converted into standard scores. By summing the two sub-set standard scores, a Gross Motor Development Quotient (GMDQ) could be obtained. The sub-set standard scores and the GMDQ could be used to determine an individual's gross motor skill performance and could be used for comparison with the standardized population score.

In regard to the reliability for the TGMD-2, the reliability coefficients for the total scale, locomotor and object control subscales were $.91, .85$ and .88 respectively (Ulrich, 2000).

\section{Procedures}

Prior to data collection, inform consent was obtained from the parents of the participants. This study was conducted by a research team, which consisted of one investigator and four testers. To assure measurement consistency, the same tester observed and scored all participants' performance for specific skill items. Equipment and assessment protocols were standardized for all participants as per the test manual of TGMD-2 (Ulrich, 2000). Testers scored each performance criteria on each trial on spot. In addition, each participant's performance was recorded by digital video camera which was set near the testers. Then the investigator reviewed the videotapes and evaluated the performances of all participants. The inter-rater percent agreement $(M=88.63 \%$, range $=$ $82.6 \%$ to $94.0 \%)$, Cohen's Kappa $(M=.85$, range $=.79$ to $93, p<.01)$ and Pearson correlation coefficient $(M=$ .88 , range $=.82$ to $.94, p<.01$ ) values indicated that the inter-rater reliability of the TGMD-2 were high (DeVellis, 2003). 


\section{Data analysis}

The Statistical Package for Social Science (SPSS for Windows, version, 13.0) was utilized to analyze the data. In regard to outlier identification, method of using standard score was adopted. The case with standard score greater than 3 or less than -3 in either skill test item was considered as outlier. From the original data set ( $N$ $=1251), 23$ outliers were identified and their cases were deleted. Accordingly, a total of 1228 cases (675 boys and 553 girls $)$ aged 3 to 10 years $(M=6.45, S D=2.10)$ were used for further analysis. The 10th, 25th, 50th, 75th and 90th percentile score equivalents for boys and girls separately for age 3-10 on the locomotor subtest, object control subtest and the total scale of the TGMD-2 were computed. These percentiles would be used to identify performance quartiles for each group (Safrit \& Wood, 1995).

\section{Results}

The raw score means and standard deviations by age and gender for the two TGMD-2 subtests were shown in Table 1. As indicated in the table, gradual increase in scores were observed over age for both male and female participants on locomotor and object control subtests.

Table 1. Raw Score Means and Standard Deviations by Age and Gender for the TGMD-2 Subtests $(\mathbf{N}=1,228)$.

\begin{tabular}{|c|c|c|c|c|c|c|c|c|c|c|}
\hline \multirow[b]{3}{*}{ Age } & \multirow[b]{3}{*}{$n$} & \multicolumn{4}{|c|}{ Male } & \multirow[b]{3}{*}{$n$} & \multicolumn{4}{|c|}{ Female } \\
\hline & & \multicolumn{2}{|c|}{ LOCO } & \multicolumn{2}{|c|}{$\mathrm{OB}$} & & \multicolumn{2}{|c|}{ LOCO } & \multicolumn{2}{|r|}{$\mathrm{OB}$} \\
\hline & & $M$ & $S D$ & $M$ & $S D$ & & $M$ & $S D$ & $M$ & $S D$ \\
\hline 3 & 50 & 20.58 & 6.78 & 12.94 & 6.45 & 65 & 23.65 & 5.89 & 12.28 & 6.45 \\
\hline 4 & 134 & 28.90 & 9.43 & 17.54 & 6.27 & 111 & 27.63 & 8.78 & 14.72 & 5.07 \\
\hline 5 & 152 & 33.59 & 6.48 & 22.97 & 7.61 & 118 & 34.05 & 6.09 & 17.99 & 5.45 \\
\hline 6 & 88 & 36.02 & 5.05 & 27.44 & 6.71 & 79 & 36.80 & 6.32 & 22.63 & 6.23 \\
\hline 7 & 58 & 41.05 & 4.35 & 30.45 & 5.69 & 69 & 41.10 & 4.06 & 27.22 & 5.64 \\
\hline 8 & 51 & 42.00 & 2.95 & 36.29 & 5.36 & 38 & 42.34 & 3.06 & 28.39 & 6.66 \\
\hline 9 & 68 & 43.43 & 3.18 & 35.54 & 6.65 & 40 & 42.63 & 3.69 & 30.10 & 5.23 \\
\hline 10 & 74 & 43.78 & 2.48 & 34.51 & 8.75 & 33 & 42.97 & 3.31 & 29.03 & 5.22 \\
\hline
\end{tabular}

Note. $L O C O=$ Locomotor subtest; $O B=$ Object control subtest.

Each gross motor skills of the TGMD-2 included several performance criteria which described the mature pattern of the skill (Ulrich, 2000). Getting full mark in the particular skill represented the acquisition of the mature form of that skill. Table 2 presented the percentage of participants who mastered a certain gross motor skills at each age from 3 through 10 years old. Overall, of the twelve gross motor skills tested in the TGMD-2, the locomotor and object skills with the highest mastery levels were "Run" and "Kick" respectively, since $67.80 \%$ and $37.06 \%$ of the total sample obtained full marks. On the other hand, the most underdeveloped locomotor skill was "Hop", with only $5.34 \%$ of the total sample demonstrated a mature form of this skill. In relation to object control skill, "Throw" was the most difficult skill for participants as only $5.35 \%$ of the total sample got full mark. 
Table 2. Percentage of Participants Demonstrating Mastery on the TGMID-2 Skill Test Items $(\mathbf{N}=1$,228).

\begin{tabular}{ccccccccc}
\hline & & \multicolumn{7}{c}{ Age } \\
Skill test item & 3 & 4 & 5 & 6 & 7 & 8 & 9 & 10 \\
\hline$n$ & 115 & 245 & 270 & 167 & 127 & 89 & 108 & 107 \\
Hop & 0.0 & 4.1 & 0.0 & 1.2 & 7.1 & 9.0 & 12.0 & 9.3 \\
Slide & 0.0 & 13.1 & 23.0 & 37.7 & 59.1 & 74.2 & 67.6 & 60.7 \\
Gallop & 0.0 & 24.1 & 31.9 & 37.7 & 77.2 & 77.5 & 74.1 & 77.6 \\
Jump & 5.2 & 33.9 & 43.7 & 59.9 & 74.8 & 78.7 & 80.6 & 86.0 \\
Leap & 6.1 & 35.1 & 41.5 & 49.1 & 48.8 & 42.7 & 72.2 & 83.2 \\
Run & 1.7 & 35.5 & 70.7 & 73.1 & 84.3 & 96.6 & 88.9 & 91.6 \\
Dribble & 0.0 & 3.7 & 5.2 & 18.0 & 38.6 & 46.1 & 47.2 & 62.6 \\
Kick & 0.0 & 1.8 & 42.2 & 63.5 & 33.9 & 36.0 & 59.3 & 59.8 \\
Catch & 0.0 & 0.0 & 1.5 & 5.4 & 12.6 & 18.0 & 10.2 & 14.0 \\
Throw & 0.0 & 0.8 & 2.2 & 1.8 & 3.1 & 13.5 & 7.4 & 14.0 \\
Roll & 0.0 & 0.0 & 1.5 & 12.0 & 3.9 & 3.4 & 14.8 & 17.8 \\
Strike & 0.0 & 2.4 & 7.4 & 7.2 & 33.9 & 37.1 & 38.9 & 46.7 \\
\hline
\end{tabular}

The 10th-, 25th-, 50th-, 75th- and 90th-percentiles score equivalent for male and female participants separately at each age from 3 through 10 years old were presented in Table 3 and 4 respectively. A percentile indicated the point in a distribution of scores below which that given percentage of scores fall. For instance, a TGMD-2 total raw score of 37 for 3 years old female fell at the 50th percentile point (Table 3, percentile for "TGMD"), hence showing that $50 \%$ of this age group had scores of 37 points or below. The age percentiles in this study also identified performance quartiles for each age group by gender.
By interpreting the age percentiles in this study, scores falling within the 25th and 75th percentiles would be considered as being in the normal range of scores, as this suggested the middle $50 \%$ of a distribution. In addition, scores lower than the 25th percentile would be considered as below average, whereas scores above 75th percentile as above average. For example, a 7-yearold boy who scored 85 points on the TGMD-2 (Table 4, percentile for "TGMD") would be evaluated as having above average gross motor skills performance for his age group. 
Table 3. Age Percentiles of Subtests and Total Raw Scores of the TGMD-2 for Female Participants $(\mathrm{n}=553)$.

\begin{tabular}{|c|c|c|c|c|c|c|c|c|}
\hline \multirow[b]{2}{*}{ Percentiles } & \multicolumn{8}{|c|}{ Age } \\
\hline & 3 & 4 & 5 & 6 & 7 & 8 & 9 & 10 \\
\hline $\begin{array}{c}n \\
\mathrm{LOCO}\end{array}$ & 65 & 111 & 118 & 79 & 69 & 38 & 40 & 33 \\
\hline 10th & 15 & 15 & 26 & 26 & 35 & 38 & 37 & 37 \\
\hline 25 th & 20 & 23 & 31 & 33 & 40 & 40 & 40 & 42 \\
\hline 50 th & 24 & 28 & 35 & 39 & 42 & 43 & 44 & 44 \\
\hline 75 th & 28 & 33 & 38 & 41 & 44 & 45 & 46 & 46 \\
\hline 90th & 31 & 40 & 42 & 44 & 46 & 46 & 46 & 47 \\
\hline OB & & & & & & & & \\
\hline 10th & 3 & 8 & 11 & 15 & 21 & 19 & 24 & 24 \\
\hline 25 th & 7 & 11 & 15 & 18 & 23 & 23 & 27 & 25 \\
\hline 50 th & 12 & 15 & 18 & 23 & 25 & 29 & 31 & 28 \\
\hline 75th & 17 & 18 & 21 & 27 & 31 & 33 & 32 & 33 \\
\hline 90th & 20 & 21 & 25 & 32 & 35 & 37 & 37 & 37 \\
\hline TGMD & & & & & & & & \\
\hline 10th & 23 & 28 & 41 & 44 & 58 & 60 & 65 & 65 \\
\hline 25th & 29 & 34 & 48 & 51 & 63 & 66 & 69 & 67 \\
\hline 50 th & 37 & 42 & 52 & 62 & 69 & 72 & 73 & 72 \\
\hline 75 th & 43 & 50 & 58 & 68 & 74 & 76 & 76 & 77 \\
\hline 90th & 48 & 56 & 63 & 70 & 77 & 79 & 82 & 81 \\
\hline
\end{tabular}

Note. $\quad$ LOCO $=$ Locomotor subtest, Maximum $=48$;

$\mathrm{OB}=$ Object control subtest, Maximum $=48$;

Table 4. Age Percentiles of Subtests and Total Raw Scores of the TGMD-2 for Male Participants ( $\mathrm{n}=675)$.

\begin{tabular}{|c|c|c|c|c|c|c|c|c|}
\hline \multirow[b]{2}{*}{ Percentiles } & \multicolumn{8}{|c|}{ Age } \\
\hline & 3 & 4 & 5 & 6 & 7 & 8 & 9 & 10 \\
\hline $\begin{array}{c}n \\
\text { LOCO }\end{array}$ & 50 & 134 & 152 & 88 & 58 & 51 & 68 & 74 \\
\hline 10th & 10 & 16 & 25 & 29 & 36 & 38 & 40 & 41 \\
\hline 25 th & 16 & 21 & 29 & 33 & 39 & 40 & 42 & 42 \\
\hline 50 th & 22 & 31 & 34 & 37 & 42 & 42 & 44 & 44 \\
\hline 75th & 26 & 37 & 38 & 40 & 44 & 44 & 46 & 46 \\
\hline $\begin{array}{l}\text { 90th } \\
\text { OB }\end{array}$ & 29 & 40 & 43 & 43 & 46 & 46 & 47 & 47 \\
\hline 10th & 2 & 10 & 13 & 18 & 22 & 29 & 27 & 23 \\
\hline 25 th & 9 & 13 & 17 & 23 & 27 & 33 & 30 & 29 \\
\hline 50 th & 13 & 17 & 22 & 27 & 30 & 36 & 37 & 34 \\
\hline 75 th & 18 & 22 & 28 & 32 & 34 & 40 & 40 & 41 \\
\hline 90th & 22 & 25 & 33 & 37 & 37 & 43 & 44 & 48 \\
\hline TGMD & & & & & & & & \\
\hline 10th & 21 & 31 & 41 & 51 & 62 & 70 & 68 & 66 \\
\hline 25 th & 26 & 37 & 49 & 57 & 67 & 74 & 73 & 72 \\
\hline 50 th & 34 & 47 & 57 & 63 & 71 & 78 & 80 & 78 \\
\hline 75th & 41 & 56 & 64 & 70 & 76 & 83 & 85 & 86 \\
\hline 90th & 49 & 61 & 70 & 75 & 80 & 86 & 88 & 91 \\
\hline
\end{tabular}

Note. $\quad$ LOCO $=$ Locomotor subtest, Maximum $=48$;

$\mathrm{OB}=$ Object control subtest, Maximum $=48$;

TGMD $=$ TGMD-2 total score, Maximum $=96$. 


\section{Discussion}

In order to depict the gross motor skills performance of Hong Kong Chinese children, normative information including percentage of participants demonstrating mastery on different skill test items in association with age percentiles of locomotor, object control subtest raw scores and total raw score of the TGMD-2 for male and female participants was provided in this study. This enabled physical educators to gain more information on the gross motor skills performance of Hong Kong Chinese children. Furthermore, this descriptive information provided a measuring index for physical educators to evaluate, consult and compare the gross motor skills performance of children.

The data collected in this study was compared to the corresponding information listed in the manual of TGMD-2, which was validated on the scores of 1208 American children. This provided a cross-cultural comparison on gross motor skills performance which was limited in previous literature. The medians of locomotor and object control subtest raw scores at age 3 through 10 of the TGMD-norms and this study were compared. The median was frequently of interest because it indicated the center of the distribution of the scores (Safrit \& Wood, 1995). The median reflected the 50th percentile, which divided the distribution so that $50 \%$ of the score fell above this point and the other 50\% fell below accordingly. The median was not affected by extreme scores, and hence it was a more representative measure of central tendency for skewed distributions (Kirk, 1984).

By interpreting the data, it was found that the locomotor skills performance of participants in this study was similar to those reported by Ulrich (2000) across different ages and gender. In contrast, the object control skills performance of participant in this study was poorer than the normative sample of the TGMD-2 of same age and gender.

In addition, by comparing the percentage of participants demonstrating mastery on different skill test items, it was found that the youngest participants in this study (age $=3$ years) performed poorly in object control subtest, since $0 \%$ of them scored full marks in any object control skill test item. In contrast, Ulrich (2000) reported that the percentage of normative sample $(n=$ 115) demonstrating mastery on the six object control skills ranged from 1\% (Catch and Roll) to $13 \%$ (Strike). Similar situations were also found in elder participants (age $=7,8,9,10$ years), as less than $20 \%$ of them showed mastery in Catch, Throw and Roll in this study, while Ulrich (2000) reported that the mastery percentage of normative sample on those skills ranged from 35\% (Strike, 7 years old, $n=165$ ) to $83 \%$ (Catch, 10 years old, $n=$ 179).

The variation in the proficiency of object control skills between Hong Kong and USA children might be explained by cultural differences. These findings agreed with others reported in literature suggesting that gross motor skills acquisition was generally determined by contextual reasons such as opportunity, parental expectations, and importance within a particular culture (Thomas, Thomas, \& Gallagher, 1993). The object control skill test items of the TGMD-2 formed the basis for many of the specific sport skills associated with popular games in western countries. For instance, the high popularity of baseball in western countries provided children with more opportunities to practice striking, throwing and rolling skills. The results of this study suggested the need for emphasis on the teaching of manipulative skills during physical education lessons in Hong Kong.

\section{Conclusion}

In conjunction with other studies, the results of this study further supported that the mastery level of gross motor skills tended to follow an age trend. In addition, this study was one of the few to examine cultural differences in gross motor skills performance beginning at the age of 3 years. It was found that Hong Kong children exhibited poorer object control skills than USA children. This highlighted the critical need for Hong Kong physical educators to design more instructional programs which focus on teaching object control skills. Furthermore, the gross motor skills performance of Hong Kong children has not been adequately addressed prior to this study. This study fills the research gap by providing profiles of gross motor skills performance of this population. The normative data provided in this study can be served as benchmark values for physical educators to evaluate gross motor skills performance of children. 


\section{References}

Barton, G. V., Fordyce, K., \& Kirby, K. (1999). Why have physical education? The importance of the development of motor skills to children. Teaching Elementary Physical Education, 10(1), 9-11.

Connor-Kuntz, F., \& Dummer, G. (1996). Teaching across the curriculum: language-enriched physical education for preschool children. Adapted Physical Activity Quarterly, 13(3), 302-315.

Curriculum Development Council. (1996). Guide to the Pre-primary Curriculum. Hong Kong Special Administrative Region of the People's Republic of China: Hong Kong.

Curriculum Development Council. (2002). Basic Education Curriculum Guide - Building on Strengths. Hong Kong Special Administrative Region of the People's Republic of China: Hong Kong.

DeVellis, R. F. (2003). Scale development: theory and applications (2nd ed.). Thousand Oaks, CA: Sage.

Kirk, R. E. (1984). Elementary statistics (2nd ed.). Monterey, CA: Brooks/Cole.

Kelly, L., Dagger, J., \& Walkley, J. (1989). The effects of an assessment-based physical education program on motor skill development in preschool children. Education and Treatment of Children, 12(2), 152-164

Luedke, G. C. (1980). Range of motion as the focus of teaching the overhand throwing pattern to children. Unpublished doctoral dissertation, Indiana University, Bloomington.

Ministry of Education. (1999). Health and physical education in the New Zealand curriculum. Wellington, New Zealand: Learning Media.

Olrich, T. W. (2002). Assessing fundamental motor skills in the elementary school setting: issues and solutions. Journal of Physical Education, Recreation \& Dance, 73(7), 26-34.
Safrit, M. J., \& Wood, T. M. (1995). Introduction to measurement in physical education and exercise science. St. Louis, MO: Mosby.

Taggart, A., \& Keegan, L. (1997). Developing fundamental movement skills in outdoor settings: Three case studies of children playing. The ACHPER Healthy Lifestyles Journal, 44(4), 11-17.

Thomas, J. R., Thomas, K. T., \& Gallagher, J. D. (1993). Developmental considerations in skill acquisition. In R. N. Singer, M. Murphey, \& L. K Tennant (Eds.), Handbook of research on sport psychology (pp. 73-105). New York: MacMillan. Ulrich, D. A. (2000). Test of gross motor development: examiner's manual (2nd ed.). Austin, TX: Pro-ed.

Ulrich, D. A. (2000). Test of gross motor development: examiner's manual (2nd ed.). Austin, TX: Pro-ed.

Woodard, R. L., \& Surburg, P. R. (2001).The performance of fundamental movement skills by elementary school children with learning disabilities.-Physical Educator, 58(4), 198-205.

\section{Correspondence}

Dr. Allison Ka Yee Wong

Department of Physical Education,

Hong Kong Baptist University,

Kowloon Tong, Hong Kong SAR. 